\title{
The Impact of the SARS-COVID-19 pandemic on mental health in population with psychiatric pathology
}

\author{
Raquel Sánchez Recio, Mariam Cristina Ait-Chaib Corchero, Gabriela Topa y Cristina García-Ael.
}

Publisher's Note: MDPI stays neutral with regard to jurisdictional claims in published maps and institutional affiliations.

\section{(c) (i)}

Copyright: (C) 2020 by the authors. Submitted for possible open access publication under the terms and conditions of the Creative Commons Attribution (CC BY) license (http://creativecommons.org/licenses/by/ $4.0 /)$.

\begin{abstract}
Context: In December 2019, the SARS-COVID19 infection is diagnosed in Wuhang (China) and it is spreading rapidly worldwide. Its impact on psychiatric patients institutionalized requires further research. Objective: This study aims to know the impact that social isolation measures have had during the COVID-19 pandemic in institutionalized patients psychiatric through a narrative review. Results: In patients with psychiatric pathology and diagnosed by COVID 19, an elevated level of symptomatology related to post-traumatic stress was obtained (96.2\%), mainly depressive symptoms $(p=.016)$. In China, patients considered that the lack of assistance and protection resources against the virus as well as the strict measures of social isolation have aggravated their illness, while patients from United States attribute the worsening of the disease to an effective diagnosis of the virus, the difficulty of implementing social distancing measures, and the lack of adequate adherence to treatment. In the Middle East, elderly psychiatric patients are doubly affected due to the lack of care resources. In fact, a French study showed that the mortality of patients with psychiatric pathology was higher than that of all other pathologies $(26.7 \%$ vs. $8.7 \%, p$ $=.039$ ). Finally, inmates psychiatric patients have worsened their pathology related to lack of psychiatric care, stress and measures taken against COVID19 in prisons. Conclusion: Little attention has been paid to the impact on the mental health of psychiatric patients. It is important to know the consequences of this pandemic in institutionalized settings, where health resources acquire an important dimension to effectively prevent both the disease caused by COVID 19 and its impact on mental health. In this sense, the work of health promotion and promotion of healthy lifestyles (more in psychiatric patients) is especially important to improve psychoneuroimmunity against COVID 19.
\end{abstract}

Keywords: Isolation; psychiatric patients; Covid, inmates 